\title{
What should be considered in terms of anesthesia in a patient with preoperative delirium
}

\author{
B. Girgin, N. Salman, S. Şekerci \\ Ankara City Hospital, Republic of Turkey \\ Що слід враховувати з точки зору анестезії
у пацієнта з передопераційним делірієм
}

Б. Гіргін, Н. Салман, С. Чекерці

Міська лікарня Анкари, Турецька Республіка

Postoperative delirium is a common complication, especially in elderly patients [1]. Recent studies have shown that postoperative delirium occurs in 10-60\% of elderly patients who have undergone surgery [2]. Although there are several therapeutic options for postoperative delirium, prevention remains the best option.

The anesthetic technique we recommend in patients with delirium is based on a multimodal approach using specific agents with anesthetic or analgesic properties; the induction of anesthesia with dexmedetomidine, lidocaine, magnesium, propofol and rocuronium and after intubation the erector spinae plain blockage that provides intraoperative and postoperative analgesia. For anesthesia maintenance lidocaine, magnesium and dexmedetomidine infusions are supplemented with low-dose inhalation agent.

In this case, we aimed to accelerate postoperative recovery, prevent delirium development and provide analgesia in patients with delirium.

A 74-year-old male patient was admitted to our hospital with abdominal pain and jaundice. He was diagnosed with hepatocellular cancer and the first operation of Associating Liver Partition and Portal Vein Ligation for Staged Hepatectomy (ALPPS) procedure was successfully performed; however, delirium developed in the patient after this first operation. The patient then stayed in the intensive care unit (ICU) until the second operation and haloperidol treatment was given. Although the agitation was controlled with this treatment, the patient had orientation and cooperation disorder before the second operation. In the second operation of this surgery technique, to prevent the development of delirium and its progression, it was decided to apply opioid-free anesthesia with lidocaine, magnesium, dexmedetomidine and erector spinae plain (ESP) blockage.

In the first operation; midazolam, lidocaine, fentanyl, propofol and rocuronium were used for anesthesia induction. For the anesthesia maintenance, $6 \%$ desflurane in 50\% $\mathrm{O}_{2} /$ air was used as an inhalation agent and remifentanil was used as an analgesic drug intraoperatively. For the postoperative pain management, morphine was used as a narcotic drug. In ICU, for the first day of the operation, tramadol was used for analgesia before delirium development.

For the second operation, in surgery room, the patient was monitored with standard electrocardiogram (ECG), heart rate, peripheral oxygen saturation $\left(\mathrm{SpO}_{2}\right)$, invasive blood pressure, bispectral index (BIS) and near infrared spectroscopy (NIRS) monitoring for ASA standards.

Preoperative blood pressure was $149 / 83 \mathrm{mmHg}$, heart rate was $89 / \mathrm{min}$ and $\mathrm{SpO}_{2}$ was $98 \%$. With radial artery catheterization, continuous blood pressure monitoring was initiated and blood gas was taken before intubation. Intubation was performed by administering $1 \mathrm{mg} / \mathrm{kg}$ lidocaine, $2.5 \mathrm{mg} / \mathrm{kg}$ propofol, $0.6 \mathrm{mg} / \mathrm{kg}$ rocuronium bromide and in addition to these drugs dexmedetomidine $1 \mathrm{mcg} / \mathrm{kg}$ bolus for 10 minutes and magnesium sulfate $20 \mathrm{mg} / \mathrm{kg}$ intravenously. After intubation, a central venous catheter was inserted through the right internal jugular vein. Subsequently, the patient was placed in the right lateral decubitus position for ESP block. We located the Philips iU22 (Andover, MA, USA) ultrasonography (USG) system with a 9-3 MHz linear transducer probe in longitudinal orientation at the level of T8 spinous process and then placed $3 \mathrm{~cm}$ laterally from the midline. Under aseptic conditions, 80 $\mathrm{mm} 21$-gauge block needle (Stimuplex(R) B-Braun medical, Melsungen, Germany) was inserted in-plane with cranial-to-caudal direction. We injected $2-3 \mathrm{~mL}$ of isotonic saline solution to confirm correct needle tip position and following hydro-dissection, we injected $10 \mathrm{~mL}$ of $0.5 \%$ bupivacaine deep to the erector spinae muscle. We repeated the same procedure with another $10 \mathrm{~mL}$ of $0.5 \%$ bupivacaine at the contralateral side for intraoperative anesthesia and postoperative analgesia. Then the patient was placed in a supine position, the surgical team dyed the patient sterile and covered him.

Anesthesia was maintained with 6\% desflurane in 50\% $\mathrm{O}_{2} /$ air with magnesium sulfate at $10 \mathrm{mg} / \mathrm{kg} / \mathrm{h}$, lidocaine at $2 \mathrm{mg} / \mathrm{kg} / \mathrm{h}$ and dexmedetomidine $0.6 \mathrm{mcg} / \mathrm{kg} / \mathrm{min}$ infusion. During the intraoperative period, the patient was replaced with 1 unit of erythrocyte suspension and 2 units of fresh frozen plasma. The patient had stable hemodynamic parameters during surgery.

$1 \mathrm{~g}$ paracetamol was applied for postoperative analgesia. The patient was extubated with $4 \mathrm{mg} / \mathrm{kg}$ sugammadex and taken to the recovery unit. The patient was observed for 45 minutes as oriented and cooperative and then referred to the ICU with Glasgow Coma Scale (GKS) value 15 and visual analogue scale (VAS) value 0 .

On the postoperative first day it was observed that the patient's delirium had gone and VAS was still 0 . He was followed 
up in the ICU for 5 days, mobilized on the postoperative first day and analgesia was administered with intermittent paracetamol infusion. No opioid requirement was observed. After the delirium and intensive care requirement disappeared, he was sent to the ward on the 5 th postoperative day.

Postoperative delirium and cognitive dysfunction are common adverse events in elderly patients. Pre-existing patient factors, drugs and various intraoperative and postoperative causes in the development of postoperative delirium and cognitive dysfunction have been demonstrated by several studies. Postoperative delirium has been reported in 13\% of these elderly patients who underwent joint replacement [3]. Advanced age is also an important risk factor for cognitive dysfunction and long recovery time after anesthesia [4]. Our case was 74 years old and so he was at risk of postoperative delirium.

Opioid analgesics are known to be the most common drugs for analgesia after major surgeries. Postoperative pain is associated with delirium and cognitive dysfunction. Opioids are routinely used in the treatment of postoperative pain and they may have central effects. There is a growing number of studies conducted to determine whether analgesic drugs or any method of reducing the delirium risks of patients. Our case with delirium and postoperative cognitive dysfunction was at risk due to major abdominal surgery and being elderly. We aimed for opioid-free anesthesia by avoiding anesthetic and analgesic approaches that could lead to delirium. We achieved this with bilateral ESP blockage using bupivacaine, which has become increasingly widespread with USG in the recent periods and has increased usage due to its long effects providing postoperative and intraoperative comfort and using magnesium, lidocaine and dexmedetomidine infusions, which benefit from their analgesic properties.

Combinations of potent opioids with non-opioids have become popular in postoperative pain management in anesthesia [5]. These multidrug regimens aim to reduce postoperative pain, perioperative opioid requirements and reduce the negative effects associated with opioid drugs. As it is known, alpha-2 agonists have suitable pharmacological properties (sedation, hypnosis, anxiolysis, sympatholysis and analgesia) as multimodal analgesia adjuvants. Antinociceptive effect is attributed to the stimulation of alpha- 2 adrenoreceptors in the central nervous system. For this reason, we aimed to use dexmedetomidine, which we believe is an important pillar of multimodal analgesia in opioid-free anaesthesia.

Magnesium which plays a vital role for analgesia is important for human homeostasis. The analgesic effects of magnesium are based on its behavior as an antagonist of N-methyl-D-aspartate (NMDA) receptors in the central nervous system. Albrecht et al. reviewed 25 randomized controlled trials (RCTs) involving 1461 patients and concluded that perioperative intravenous magnesium infusion could reduce opioid consumption and pain scores in the first 24 hours postoperatively [6]. In this case with delirium in the preoperative period of the second surgery, it was shown that intravenous lidocaine infusion has analgesic, anti-inflammatory and antihyperalgesic properties. So that for opioid-free anesthesia, intraoperative magnesium-lidocaine infusion was applied by taking advantage of analgesic properties of them.
Intraoperative and postoperative analgesia technique and the use of inhalation agents in the maintenance of anesthesia may reduce postoperative delirium risk compared to propofol and provide a faster postoperative recovery due to the more complex and variable pharmacokinetic mechanism associated with propofol. For example, in geriatric patients who undergo surgery due to short urological procedures, patients achieve much faster recovery criteria after anesthesia using desflurane. Many studies suggest that inhalation anesthesia may be associated with less postoperative cognitive dysfunction and postoperative delirium than total intravenous anesthesia using propofol [7]. We performed anesthesia maintenance with desflurane in order to reduce or even eliminate the risk of postoperative cognitive dysfunction and delirium.

\section{Conclusion}

Therefore, in our elderly patient who was treated for delirium in the postoperative period, to prevent the development of delirium and its progression, it was decided to apply opioid-free anesthesia with lidocaine, magnesium, dexmedetomidine and erector spinae plain (ESP) blockage. We would like to share with you this multimodal approach and to emphasize the important roles of the agents we use in this case.

\section{References}

1. Guenther U, Radtke FM. Delirium in the postanaesthesia period. Curr Opin Anaesthesiol. 2011 Dec;24(6):670-5. doi: 10.1097/ACO. 0b013e32834c7b44. PMID: 21971396.

2. Deiner S, Silverstein JH. Postoperative delirium and cognitive dysfunction. Br J Anaesth. 2009 Dec;103 Suppl 1(Suppl 1):i41-46. doi: 10.1093/bja/aep291. PMID: 20007989; PMCID: PMC2791855.

3. Zywiel MG, Prabhu A, Perruccio AV, Gandhi R. The influence of anesthesia and pain management on cognitive dysfunction after joint arthroplasty: a systematic review. Clin Orthop Relat Res. 2014 May;472(5):1453-66. doi: 10.1007/s11999-013-3363-2. PMID: 24186470 ; PMCID: PMC3971229.

4. Hartholt KA, van der Cammen TJ, Klimek M. Postoperative cognitive dysfunction in geriatric patients. Z Gerontol Geriatr. 2012 Jul;45(5):411-6. doi: 10.1007/s00391-012-0326-2. PMID: 22538789.

5. Rasmussen ML, Mathiesen O, Dierking G, Christensen BV, Hilsted KL, Larsen TK, et al. Multimodal analgesia with gabapentin, ketamine and dexamethasone in combination with paracetamol and ketorolac after hip arthroplasty: a preliminary study. Eur J Anaesthesiol. 2010 Apr;27(4):324-30. doi: 10.1097/EJA.0b013e328331c71d. PMID: 19734790.

6. Albrecht E, Kirkham KR, Liu SS, Brull R. Peri-operative intravenous administration of magnesium sulphate and postoperative pain: a meta-analysis. Anaesthesia. 2013 Jan;68(1):79-90. doi: 10.1111/j.13652044.2012.07335.x. Epub 2012 Nov 1. PMID: 23121612.

7. Schoen J, Husemann L, Tiemeyer C, Lueloh A, Sedemund-Adib B, Berger KU, et al. Cognitive function after sevoflurane- vs propofol-based anaesthesia for on-pump cardiac surgery: a randomized controlled trial. Br J Anaesth. 2011 Jun;106(6):840-50. doi: 10.1093/ bja/aer091. Epub 2011 Apr 25. PMID: 21518736.

Received: 24.12 .2020 